Analysis of 2012 Meteorological Data from the Knolls Atomic Power Laboratory and Kesselring Site Operations Facilities

F. J. Aluzzi

February 15, 2013 
This document was prepared as an account of work sponsored by an agency of the United States government. Neither the United States government nor Lawrence Livermore National Security, LLC, nor any of their employees makes any warranty, expressed or implied, or assumes any legal liability or responsibility for the accuracy, completeness, or usefulness of any information, apparatus, product, or process disclosed, or represents that its use would not infringe privately owned rights. Reference herein to any specific commercial product, process, or service by trade name, trademark, manufacturer, or otherwise does not necessarily constitute or imply its endorsement, recommendation, or favoring by the United States government or Lawrence Livermore National Security, LLC. The views and opinions of authors expressed herein do not necessarily state or reflect those of the United States government or Lawrence Livermore National Security, LLC, and shall not be used for advertising or product endorsement purposes.

This work performed under the auspices of the U.S. Department of Energy by Lawrence Livermore National Laboratory under Contract DE-AC52-07NA27344. 


\section{Table of Contents}

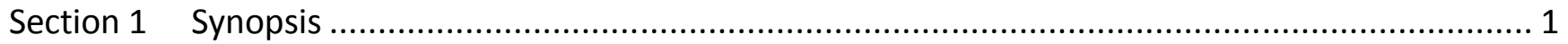

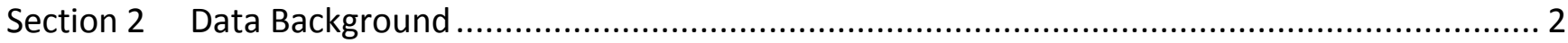

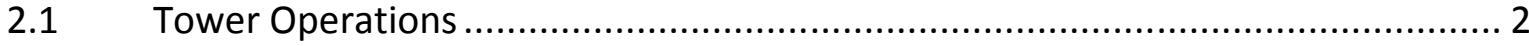

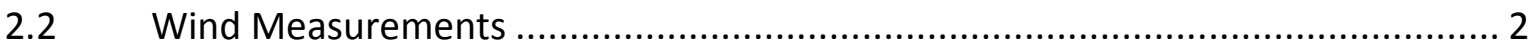

$2.3 \quad$ Time Zone Convention ........................................................................... 3

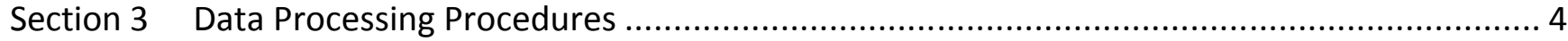

3.1 Quality Assurance of 15-minute Averaged Data .......................................... 4

3.2 Hourly Averaging ................................................................................ 5

3.3 Modified Sigma Theta (MST) Method ….................................................. 7

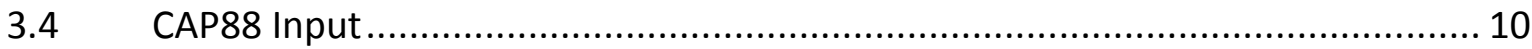

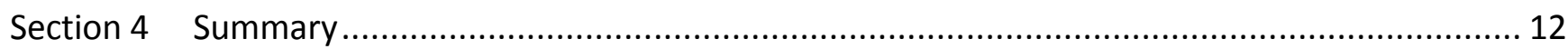

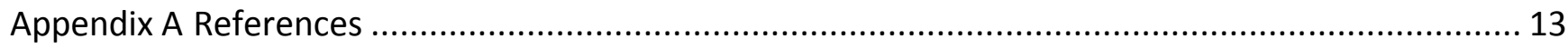




\section{Section 1. Synopsis}

Both the Knolls Atomic Power Laboratory (KAPL) in Schenectady, N.Y. and the Kesselring Site Operations (KSO) facility near Ballston Spa, N.Y. are required to estimate the effects of hypothetical emissions of radiological material from their respective facilities by the U.S. Environmental Protection Agency (EPA), which regulates these facilities. An atmospheric dispersion model known as CAP88, which was developed and approved by the EPA for such purposes, is used by KAPL and KSO to meet this requirement. CAP88 calculations over a given time period are based on statistical data on the meteorological conditions for that period.

Both KAPL and KSO have on-site meteorological towers which take atmospheric measurements at a frequency ideal for EPA regulatory model input. However, an independent analysis and processing of the meteorological data from each tower is required to derive a data set appropriate for use in the CAP88 model. The National Atmospheric Release Advisory Center (NARAC) was contracted by KAPL to process the on-site data for the calendar year 2012.

The purpose of this document is to:

- Summarize the procedures used in the preparation/analysis of the 2012 meteorological data

- Document adherence of these procedures to the guidance set forth in "Meteorological Monitoring Guidance for Regulatory Modeling Applications", EPA document: EPA-454/R-99-005 (EPA-454) 


\section{Section 2. Data Background}

\subsection{Tower Operations}

The meteorological towers at KAPL and KSO are maintained by NARAC (via a subcontract with Air Resource Specialists [ARS]), in coordination with site facility personnel. The role of NARAC in tower instrument maintenance is independent from its role in this analysis.

Both of the towers are equipped with identical sets of meteorological instrumentation for measuring the following ambient parameters:

- Air temperature

- Relative humidity

- Wind speed

- Wind direction

- Precipitation as accumulation over 15-minute periods

The sensors on the two towers are affixed at the following heights (above ground level):

- $\mathrm{KAPL}-13$ meters

- $\mathrm{KSO}-43$ meters

The tower instruments take measurements at a frequency of a few seconds. These direct measurements are then collected and averaged over 15 minute periods by a data acquisition system (datalogger) from Campbell Scientific (http://www.campbellsci.com).

\subsection{Wind Measurements}

Both towers are equipped with two sets of wind measuring instruments:

- A sonic wind sensor (Ultrasonic Wind Sensor WS425) from the Vaisala Corporation. (http://www.vaisala.com/Vaisala Documents/User Guides and Quick Ref Guides/WS425 User Guide in English.pdf)

- A mechanical wind sensor using a mechanically driven propeller and wind vane from the R. M. Young Company (http://www.youngusa.com/products/7/8.html)

Both wind sensors operate simultaneously and independently, resulting in two sets of wind measurements and two sets of 15-minute averaged wind values.

While the sonic and mechanical wind instruments are co-located in order to measure the same ambient wind conditions, they operate in a markedly different manner. The sonic instrumentation, having no moving parts, responds much quicker to changes in wind flow. This quicker response time has two important consequences: 
- The sonic sensor tends to produce sigma theta values that are noticeably larger than those resulting from the mechanical sensor. Sigma theta is a key parameter in the hourly averaging methodology used in this analysis and is determined from changes in the wind direction over time.

- The difference in instrument sensitivity results in a lower calm wind threshold for the sonic sensor. The calm wind threshold is the minimum ambient wind speed needed to engage a wind speed sensor (anemometer) to obtain a valid reading. The manufacturer specification for the mechanical anemometer has a reported calm wind threshold of $1.1 \mathrm{~m} / \mathrm{s}$. In contrast, the threshold for the sonic anemometer is much lower and is reported to be "virtually zero". EPA454 provides guidance on the treatment of calm winds for mechanical instrumentation but states, "sonic anemometers are not commonly used for routine monitoring and are beyond the scope of this guide."

During the collection and averaging of the 15-minute data, the datalogger performs a series of data quality assurance tests. These tests are performed separately on the sonic and mechanical wind measurements as well as on other non-wind measurements. These tests can result in either or both of the wind sensors being flagged as suspect during a given 15-minute period.

\subsection{Time Zone Convention}

All times in this document are given in UTC (Universal Time Coordinates or Greenwich Mean Time). Eastern Standard Time, the standard time zone for both KAPL and KSO, is 5 hours earlier than UTC. 


\section{Section 3. Data Processing Procedures}

\subsection{Quality Assurance of 15-minute Averaged Data}

In preparation for the calculation of hourly averages for both sites, a concentrated effort was made to gather the most complete, consistent and reliable data set of 15-minute averages over the 2012 calendar year.

Data recovery was nearly complete for the entire 2012 period as all of the 15 -minute averaged data was retrieved for KSO and very close to $100 \%$ was retrieved for KAPL. For the latter site, only six consecutive 15-minute averages were missing out of a total of 35,136 (366 days per year $x 24$ hours per day $\times 4$ 15minute averages per hour). These missing values at KAPL all occurred consecutively during May 24 . One single 15-minute average at KSO was removed due to the wind values looking suspect.

To avoid the need to compensate for the differences between the behavior of the sonic and mechanically based wind sensors described in Section 2, 15-minute averages were gathered only from the sonic sensors. A search was performed to identify duplicated values from one 15-minute period to the next. Each 15-minute average consists of five wind related parameters: speed, direction, gusts, sigma theta, and the standard deviation in wind speed. There were isolated cases in both data sets in which these five wind parameters were duplicated between successive 15-minute periods. These were considered erroneous as it is extremely unlikely that data from two successive 15-minute periods, based on 200 to 400 instantaneous measurements only seconds apart, would produce the same exact results. A total of seventy 15-minute averages at KAPL and sixty three 15-minute averages at KSO were found to be duplications of the preceding period. These duplicated values were removed from the final data set, while the preceding periods were retained. For example, if the wind averages were identical at 2:15 and 2:30 the data at 2:30 would be removed while keeping the 2:15 values.

Hourly periods resulting in less than four valid 15-minute averages were therefore due to missing data (KAPL), the single removed average at KSO, or the removal of duplicated values. Table 1 summarizes the resulting count of valid 15-minute averages within each hourly period out of the possible 8784 hours ( 366 days $x 24$ hours per day) in the 2012 data set.

\begin{tabular}{lccllc}
\hline & $\begin{array}{l}\text { Hourly } \\
\text { periods with 4 } \\
\text { valid 15-min } \\
\text { averages }\end{array}$ & $\begin{array}{l}\text { Hourly } \\
\text { periods with 3 } \\
\text { valid 15-min } \\
\text { averages }\end{array}$ & $\begin{array}{l}\text { Hourly } \\
\text { periods with 2 } \\
\text { valid 15-min } \\
\text { averages }\end{array}$ & $\begin{array}{l}\text { Hourly } \\
\text { periods with 1 } \\
\text { valid 15-min } \\
\text { average }\end{array}$ & $\begin{array}{l}\text { Hours with 0 } \\
\text { valid 15-min } \\
\text { average }\end{array}$ \\
\hline KAPL & 8714 & 66 & 3 & 0 & 1 \\
KSO & 8720 & 64 & 0 & 0 & 0 \\
\hline
\end{tabular}

Table 1 - Count of valid 15-minute averaged data sets within each hourly period over 2012 
EPA-454 guidance states any hourly period must have at least two of the possible four 15-minute averages to be considered valid. As Table 1 shows, only one hourly period, at KAPL, did not meet this requirement due to the aforementioned missing 15-minute averaged data on May 24 . The data recovery at KSO was excellent as there were no hourly periods with less than three valid 15-minute averages.

\subsection{Hourly Averaging}

The eventual data format required by CAP88 is a joint frequency distribution of wind speed, direction, and atmospheric stability. Such a distribution shows the percentage of occurrence of all possible combinations of these parameters. Since wind speed and direction are measured directly by the tower instrumentation, the hourly averages of these two parameters suffice as input into the joint frequency distribution. However, a method is needed to determine atmospheric stability at each hour.

There are four methods recommended in EPA-454 for calculating the atmospheric stability, but only one of these methods could be used in this analysis based on the parameters measured on the site towers. This method is the commonly used "Modified Sigma Theta" (MST) method which is based on hourly averages of the:

- Wind speed

- Wind direction

- Sigma theta

The computation of an hourly averaged value for each meteorological variable of interest was based on the four 15-minutes averages ending at the top of that hour. For example, an hourly average at 3:00 UTC was calculated as the average of the four 15-minute averages from 2:15, 2:30, 2:45 and 3:00 UTC.

\subsubsection{Averaging Equations}

The hourly averaging performed in this analysis used the following equations from EPA-454:

- Wind speed - Scalar wind speed equation (EPA-454 Eq.6.2.1):

$$
\overline{\mathrm{u}}=\frac{1}{N} \sum_{1}^{N} u_{i}
$$

where $\overline{\mathrm{u}}=$ average wind speed, and $N=$ the number of 15-minute averages in each hourly period. This is an arithmetic average of the 15-minute averaged wind speeds.

- Wind Direction - Scalar mean wind direction equation (EPA-454 Eq. 6.2.4):

$$
\bar{\Theta}=\frac{1}{N} \sum_{1}^{N} \mathrm{D}_{i}
$$




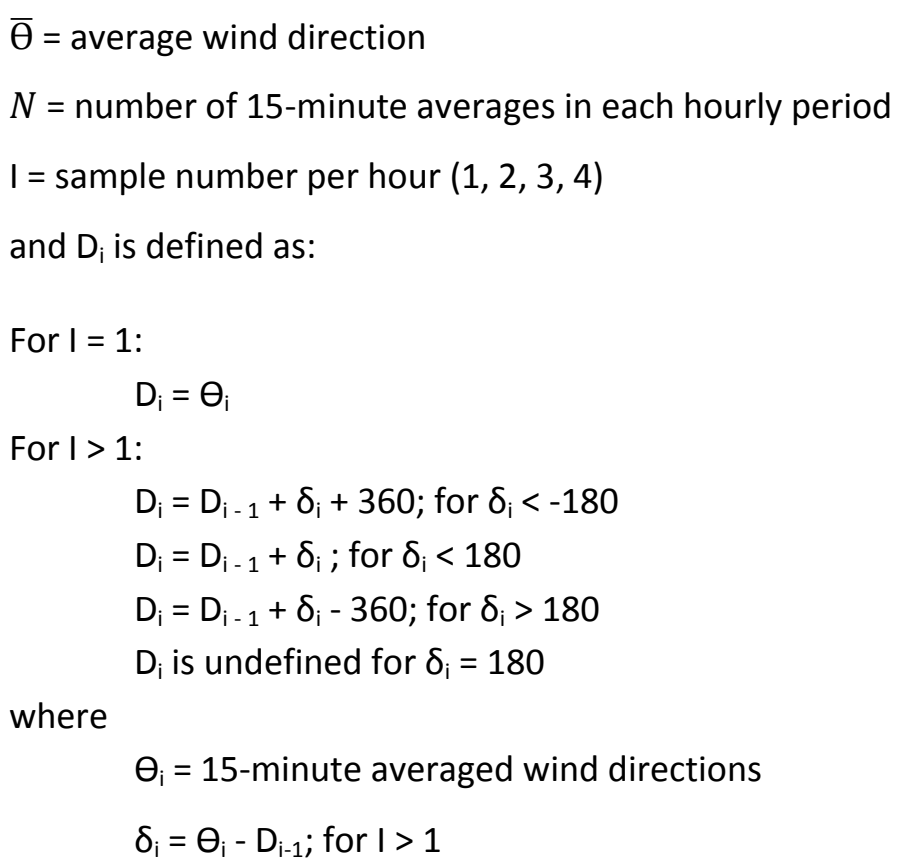

Being a scalar average, this formula computes the average wind direction without the need for calculating the vector components of the wind directions. This averaging method is based on the assumption that the wind direction does not vary by more than 180 degrees between successive readings. There were approximately ten occurrences among both sites with consecutive 15-minute averaged wind direction differing by exactly 180 degrees. In those cases, a visual inspection of the data was used to determine the appropriate average

- Sigma theta - root-mean-square "average" (EPA-454, eq. 6.2.10)

$$
\text { Hourly sigma theta }=\left[\frac{1}{N}\left\{\sum_{1}^{N} \sigma_{\theta_{\mathrm{i}}}^{2}\right\}\right]^{1 / 2}
$$

where $\sigma_{\theta_{\mathrm{i}}}$ is the 15-minute averaged sigma theta value, and $\mathrm{N}$ is the number of 15 -minute averages. This root-mean-square formula is recommended by EPA-454 in order to minimize the effects of wind meandering as opposed to a straight arithmetic average.

In the case of wind speed and direction, EPA-454 also allows for vector based averaging as opposed to the scalar based equations. However, that document recommends the scalar averaging approach if possible as was used in this analysis. 


\subsubsection{Hourly Averaged Calm Wind Values}

In order to define a calm wind threshold for this analysis, the ability of the sonic anemometer to measure wind speeds at values close to zero must be coordinated with EPA guidance on the treatment of calm winds along with the requirements of CAP88. Since the CAP88 model's defined minimum wind speed is $1 \mathrm{knot}$, an effective minimum wind speed in this analysis was taken to be $0.26 \mathrm{~m} / \mathrm{s}$ (1 knot), even though the sonic can measure much lower speeds.

Hourly calm wind values, i.e. wind speeds less than 1 knot, were therefore not included in the final 2012 frequency distribution for input into CAP88. There were very few such values in the hourly averaged 2012 data at either site: three at KAPL and only one at KSO.

\subsection{Modified Sigma Theta (MST) Method}

The MST method is a turbulence based method of characterizing atmospheric stability through the degree of variation in wind direction, sigma theta, as measured in the raw data. The correspondence between Pasquill-Gifford (PG) atmospheric stability categories and sigma theta is given by Table 2 below:

\begin{tabular}{|c|c|}
\hline $\begin{array}{c}\text { Measured Deviation of Horizontal Wind } \\
\text { Direction } \\
\text { in units of compass degrees) }\end{array}$ & $\begin{array}{c}\text { Initial } \\
\text { estimate of P- } \\
\text { G Stability } \\
\text { Category }\end{array}$ \\
\hline $22.5 \leq \sigma_{\theta}$ & A \\
\hline $17.5 \leq \sigma_{\Theta}<22.5$ & B \\
\hline $12.5 \leq \sigma_{\Theta}<17.5$ & $\mathrm{C}$ \\
\hline $7.5 \leq \sigma_{\Theta}<12.5$ & $\mathrm{D}$ \\
\hline $3.8 \leq \sigma_{\Theta}<7.5$ & $\mathrm{E}$ \\
\hline$\sigma_{\Theta}<3.8$ & $\mathrm{~F}$ \\
\hline
\end{tabular}

Table 2 - PG-stability correspondence to sigma theta data (reproduced from EPA-454: Table 6-9a).

These categories do not take into account site specific characteristics. Therefore, adjustments of these categories was required by the MST for both KAPL and KSO in order to correct for the height at which the measurements are taken and the surface roughness.

Once the necessary site specific corrections are made to Table 2 (EPA-454: Table 6-9a), for each hourly average the MST method: 
- Uses the site specific sigma theta ranges, shown in Table 4 below, to determine an initial value of the Pasquill-Gifford (PG) stability based on the hourly averaged sigma theta values

- Uses the initial PG stability, day/night classification, and wind speed values to determine a more comprehensive value for stability using a second lookup table EPA-454: Table 6-9b

These steps are discussed in more detail in the following sub-sections.

\subsubsection{Site Specific Corrections}

The MST requires an estimate of the surface roughness length for each site. Surface roughness estimates were initially made based on discussions with KAPL staff. These estimates were then compared to EPA-454 (Table 6-10), which provides surface roughness estimates based on terrain characteristics, as well as the American Meteorological Society's surface roughness equation (e/30; where $\mathrm{e}=$ averaged height of obstacles). The final estimate of surface roughness for each site is an approximate average of all of these sources.

The surface roughness lengths for each site were finalized as:

- KAPL: 0.30 meters

- $\quad \mathrm{KSO}: 0.25$ meters

Since these two values do match the standard surface roughness length of 0.15 meters assumed in Table 2, EPA-454 (section 6.4.4) provides the following surface roughness correction factor:

- $\left(Z_{0} / 15\right)^{0.2} \quad Z_{0}=$ site surface roughness length (in centimeters)

The sigma theta ranges in Table 2 also assume an instrument height of 10 meters. Since the instrument height at both sites differs from this standard level (13 m at KAPL, $43 \mathrm{~m}$ at KSO), a correction factor from EPA-454, section 6.4.4 was applied. This measurement height correction factor is given by:

$$
\text { - }(\mathrm{Z} / 10)^{\wedge} \mathrm{P}_{0}
$$

where $\mathrm{Z}$ = the measurement height in meters, and $\mathrm{P}_{0}$ is a function of stability based on the following table:

\begin{tabular}{|c|c|c|c|c|c|c|}
\hline PG Stability & A & B & C & D & E & F \\
\hline$P_{0}$ & -0.06 & -0.15 & -0.17 & -0.23 & -0.38 & 0 \\
\hline
\end{tabular}

Table 3 - Stability-dependent exponent values for instrumentation height correction (EPA-454).

The surface roughness and height corrections at each site were multiplied by the lower boundary of each stability category in Table 2, resulting in adjusted site specific sigma theta ranges in accordance with EPA-454. The corrected sigma theta ranges for determining the initial estimate of PG stability are shown below in Table 4. These adjusted sigma theta ranges were then used to determine an initial atmospheric stability class for each hour. 


\begin{tabular}{|c|c|c|}
\hline KAPL & KSO & $\begin{array}{c}\text { Initial estimate of } \\
\text { PG Stability } \\
\text { Category }\end{array}$ \\
\hline $25.4 \leq \sigma_{\ominus}$ & $22.8 \leq \sigma_{\ominus}$ & $\mathrm{A}$ \\
\hline $19.3 \leq \sigma_{\Theta}<25.4$ & $15.6 \leq \sigma_{\Theta}<22.8$ & $\mathrm{~B}$ \\
\hline $13.7 \leq \sigma_{\Theta}<19.3$ & $10.8 \leq \sigma_{\Theta}<15.6$ & $\mathrm{C}$ \\
\hline $8.1 \leq \sigma_{\ominus}<13.7$ & $5.9 \leq \sigma_{\Theta}<10.8$ & $\mathrm{D}$ \\
\hline $4.0 \leq \sigma_{\Theta}<8.1$ & $2.4 \leq \sigma_{\Theta}<5.9$ & $\mathrm{E}$ \\
\hline$\sigma_{\Theta}<4.0$ & $\sigma_{\Theta}<2.4$ & $\mathrm{~F}$ \\
\hline
\end{tabular}

Table 4 - Modified version of EPA-454 Table 6-9a used in this analysis.

\subsubsection{Day/Night Calculations}

For the calculation of the final stability at each hour, the MST method requires that each hour be identified as occurring during the day or night. The determination of day or night periods are based on an Excel spreadsheet available from Greg Pelletier from the Department of Ecology, WA. The calculations within that spreadsheet are described at the following NOAA web sites:

- "Sunrise/Sunset Calculator" (http://www.srrb.noaa.gov/highlights/sunrise/sunrise.html)

- "Solar Position Calculator" (http://www.srrb.noaa.gov/highlights/sunrise/azel.html)

Day and night values were calculated from the NOAA program based on the solar elevation angle for each hour in the calendar year. A positive/negative solar elevation angle generated by the NOAA calculator was interpreted as a day/night value. An adjustment was made to the calculated day hours just after sunrise and before sunset for consistency with the definition of day and night in Table 6-3 of EPA-454: "Night refers to the period from one hour before sunset to one hour after sunrise". Therefore the first and last day time hours in a given day, based on solar elevation, were re-categorized as night time hours.

Due to the relative proximity and approximate equality of solar parameters between the two facilities, one set of day/night values was calculated at a geographic point approximately half-way between KAPL and KSO and used for both sites. 


\subsubsection{Final Pasquill-Gifford Stability Estimates}

Table 5 (which reproduces EPA-454: Table 6-9b) was used to determine the final stability values from the initial PG classification, the day/night designation, and the wind speed.

\begin{tabular}{|c|c|c|c|}
\hline & $\begin{array}{l}\text { Initial } \\
\text { Estimate of } \\
\text { PG Stability }\end{array}$ & wind speed & $\begin{array}{l}\text { Final } \\
\text { Estimate of } \\
\text { PG Stability }\end{array}$ \\
\hline \multirow{10}{*}{ Daytime } & A & $\mathrm{u}<3$ & A \\
\hline & A & $3 \leq \mathrm{u}<4$ & B \\
\hline & A & $4 \leq \mathrm{u}<6$ & $\mathrm{C}$ \\
\hline & A & $6 \mathrm{u}$ & $\mathrm{D}$ \\
\hline & B & $\mathrm{u}<4$ & B \\
\hline & B & $4 \leq u<6$ & $\mathrm{C}$ \\
\hline & $\mathrm{B}$ & $6 \mathrm{u}$ & $\mathrm{D}$ \\
\hline & $\mathrm{C}$ & $\mathrm{u}<6$ & $\mathrm{C}$ \\
\hline & $\mathrm{C}$ & $6 \mathrm{u}$ & $\mathrm{D}$ \\
\hline & $\mathrm{D}, \mathrm{E}$, or $\mathrm{F}$ & any & $\mathrm{D}$ \\
\hline \multirow{14}{*}{ Nighttime } & A & $\mathrm{u}<2.9$ & $F$ \\
\hline & A & $2.9 \leq \mathrm{u}<3.6$ & $\mathrm{E}$ \\
\hline & A & $3.6 \mathrm{u}$ & D \\
\hline & B & $\mathrm{u}<2.4$ & $\mathrm{~F}$ \\
\hline & $\mathrm{B}$ & $2.4 \leq \mathrm{u}<3.0$ & E \\
\hline & B & $3.0 \mathrm{u}$ & $\mathrm{D}$ \\
\hline & $\mathrm{C}$ & $\mathrm{u}<2.4$ & $\mathrm{E}$ \\
\hline & $\mathrm{C}$ & $2.4 \mathrm{u}$ & $\mathrm{D}$ \\
\hline & $\mathrm{D}$ & any & $\mathrm{D}$ \\
\hline & $\mathrm{E}$ & $\mathrm{u}<5$ & $\mathrm{E}$ \\
\hline & $\mathrm{E}$ & $5 \mathrm{u}$ & $\mathrm{D}$ \\
\hline & $\mathrm{F}$ & $\mathrm{u}<3$ & $\mathrm{~F}$ \\
\hline & $\mathrm{F}$ & $3 \leq \mathrm{u}<5$ & E \\
\hline & $\mathrm{F}$ & $5 \mathrm{u}$ & $\mathrm{D}$ \\
\hline
\end{tabular}

Table 5 - Final stability values for Modified Sigma Theta method incorporating day/night and wind speed values (EPA-454: Table 6-9b). 


\subsection{CAP88 Input}

The deliverable product required from this analysis was a summary of the hourly stabilities and wind values for use in running the CAP88 program. The standard CAP88 input format for meteorological data is an ASCII "Wind File" (WND). The WND file was generated via a CAP88-provided utility which uses as input a joint frequency table of stability and winds in "Stability Array file" (STAR) format.

The LLNL analysis created appropriate STAR files for each site. To create the STAR file, the hourlyaveraged wind data was processed as follows:

- Each hourly wind direction was converted to its corresponding sector: e.g. NNE or North/Northeast

- Wind speed units were converted from $\mathrm{m} / \mathrm{s}$ to knots and rounded to whole integers

A LLNL-developed program was then used to process the hourly wind and corresponding Pasquill-Gifford stability categories into the appropriate joint frequency category and count those values accordingly. 


\section{Section 4. Summary}

This document outlines the steps in analyzing and processing meteorological data from the Knolls Atomic Power Laboratory and Kesselring Site Operations facilities into a format that is compatible with the steady state dispersion model CAP88. This process is based on guidance from the EPA regarding the preparation of meteorological data for use in regulatory dispersion models. The analysis steps outlined in this document can be easily adapted to process data sets covering time periods other than one year. The procedures will need to be modified should the guidance in EPA-454 be updated or revised. 


\section{References}

United States Environmental Protection Agency, Office of Air Quality Planning and Standards, Meteorological Monitoring Guidance for Regulatory Modeling Applications (EPA-454/R-99-005), February 2000. 


\section{Disclaimer}

This document was prepared as an account of work sponsored by an agency of the United States government. Neither the United States government nor Lawrence Livermore National Security, LLC, nor any of their employees makes any warranty, expressed or implied, or assumes any legal liability or responsibility for the accuracy, completeness, or usefulness of any information, apparatus, product, or process disclosed, or represents that its use would not infringe privately owned rights. Reference herein to any specific commercial product, process, or service by trade name, trademark, manufacturer, or otherwise does not necessarily constitute or imply its endorsement, recommendation, or favoring by the United States government or Lawrence Livermore National Security, LLC. The views and opinions of authors expressed herein do not necessarily state or reflect those of the United States government or Lawrence Livermore National Security, LLC, and shall not be used for advertising or product endorsement purposes.

\section{Auspices}

This work was performed under the auspices of the U.S. Department of Energy by Lawrence Livermore National Laboratory under Contract DE-AC52-07NA27344. 